\title{
A FORMAÇÃO INICIAL E CONTINUADA DE EDUCADORES MUSEAIS: PROJETO EM CONSTRUÇÃO
}

\author{
INITIAL AND CONTINUING TRAINING OF MUSEUM EDUCATORS: \\ PROJECT UNDER CONSTRUCTION
}

\section{FORMACIÓN INICIAL Y CONTINUA DE EDUCADORES EN MUSEOS: PROYECTO DE CONSTRUCCION}

Andréa Fernandes Costa ${ }^{1}$

\section{RESUMO}

$\mathrm{O}$ entendimento acerca das especificidades da função educativa dos museus passou por importantes transformações, mas pouco se avançou no que diz respeito à formação dos educadores museais. A literatura sobre o tema aponta para o predomínio da formação no desenvolver da própria prática profissional e destaca a pouca presença de instâncias acadêmicas voltadas para a formação dos mesmos. No presente artigo abordaremos discussões acerca do perfil dos educadores museais, das práticas e dos desafios referentes à formação inicial e continuada destes, tanto no cenário nacional quanto no internacional. Fazemos considerações acerca de iniciativa voltada à formação de profissionais nesse campo em nível de pós-graduação, bem como de ações em diferentes formatos desenvolvidas mais recentemente no Rio de Janeiro.

PALAVRAS-CHAVE: Educação Museal. Perfil dos educadores museais. Formação inicial. Formação continuada.

\section{ABSTRACT}

The understanding of the specificities of the educational function of museums has undergone important changes, but little progress has been made regarding the training of museum educators. The literature on the subject points to the predominance of training in the development of their own professional practice and highlights the little presence of academic instances focused on their formation. In the present article we will discuss about the profile of the museal educators, the practices and the challenges related to their initial and continuous formation, both in the national and international scenario. We make considerations about the initiative aimed at training professionals in this field at postgraduate level, as well as actions in different formats developed most recently in Rio de Janeiro.

KEYWORDS: Museum Education. Profile of museum educators. Initial formation. Continuing formation.

Submetido em: 20/08/2019 Aceito em: 26/08/2019 Publicado em: 31/08/2019.

${ }^{1}$ Educadora museal na Seção de Assistência ao Ensino do Museu Nacional (UFRJ), Professora do Departamento de Estudos e Processos Museológicos e da Escola de Museologia (UNIRIO), Mestre e Doutoranda em Educação (PPGEdu/UNIRIO). Integrante do Grupo de Pesquisa Educação Museal: história, conceitos e políticas do diretório do IBRAM no CNPq, coordenado pela Profa Dra Fernanda Castro. 


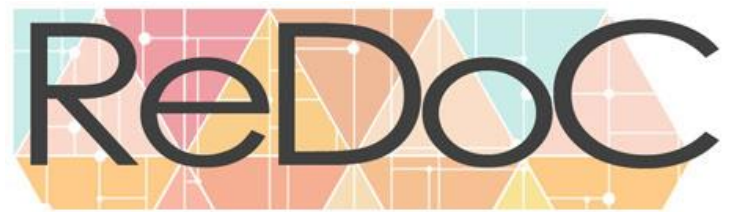

Revista Docência e Cibercultura

\section{RESUMEN}

La comprensión de las especificidades de la función educativa de las instituciones museísticas experimentó importantes transformaciones, pero se hicieron pocos progresos con respecto a la capacitación de los educadores de museos. La literatura sobre el tema apunta al predominio de la capacitación en el desarrollo de su propia práctica profesional y destaca la poca presencia de instancias académicas centradas en su formación. En el presente artículo discutiremos sobre el perfil de los educadores museales, las prácticas y los desafíos relacionados con su formación inicial y continua, tanto en el escenario nacional como internacional. Consideramos la iniciativa dirigida a la formación de profesionales en este campo a nivel de posgrado, así como las acciones en diferentes formatos desarrolladas más recientemente en Río de Janeiro.

PALABRAS CLAVE: Educación en museos. Perfil de educadores de museos. Formación inicial. Formación continua.

\section{A FORMAÇÃO DE PROFISSIONAIS NO CAMPO DA EDUCAÇÃO MUSEAL: UMA URGÊNCIA DE DÉCADAS}

O reconhecimento de que é necessário um profissional com formação específica para atuar no campo da educação museal não é recente e está registrado na literatura especializada e em documentos que se inserem no contexto de políticas públicas para o campo há pelo menos seis décadas.

Aconteceu no Rio de Janeiro, no ano de 1958, o Seminário Regional da Unesco sobre a Função Educativa dos Museus. O evento integrou um conjunto de seminários sobre o tema, tendo sido realizados eventos internacionais no ano de 1952, em Nova York (1952), e na cidade de Atenas, em 1954. O evento de 1958 é considerado um dos marcos da Museologia e contribuiu para o fortalecimento da educação museal no Brasil. A formação dos profissionais de museus foi abordado de maneira consistente no evento e, por meio da análise do relatório elaborado por Georges Henry Rivière (1960), podemos identificar as principais propostas e os maiores desafios colocados naquele momento à formação de profissionais de museus, de modo geral, e de educadores de museus, de maneira particular.

O tema foi abordado no Seminário sob o título "Ensino e aperfeiçoamento profissional do pessoal dos museus" e considerou aspectos como a formação básica, a formação museológica geral, formações museológicas especializadas, ingresso na profissão e aperfeiçoamento, 


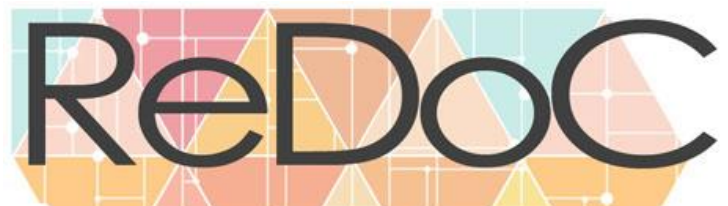

\section{Revista Docência e Cibercultura}

dentre outros. Ao se abordar a formação básica, são elencadas algumas categorias profissionais e os desejáveis títulos para o exercício de suas funções. Dentre as categorias abordadas está a de educador de museu (educateur de musée), para a qual se considerava desejável o cargo de bacharel em artes ou em ciências, de acordo com a especialidade requerida pelo museu. No âmbito das formações museológicas especializadas a função de educador é novamente citada e, para seu exercício, se considera o diploma geral de museologia suficiente, desde que o estudante buscasse cursos práticos prolongados nos museus da especialidade desejada e que possibilitassem ao mesmo a participação na realização de programas educativos, bem como a familiarização com os objetos como meio de informação, desenvolvendo o contato com o público. Seus conhecimentos sociais e econômicos da comunidade.

No ano de 1958 se apontava como um problema para a formação de profissionais para atuar nos museus o fato de um grande número de países, em especial aqueles da América Latina, não contarem "nem com uma verdadeira escola de museu" e nem com "simples cursos de Museologia” (RIVIÉRE, 1960, p.15). Outro desafio a ser superado dizia respeito às próprias transformações pelas quais a instituição museu havia passado, fazendo com que a atualização dos profissionais no campo demandasse outras formações que não só a museológica. Assim sendo, se defendia como forma de superação de alguns dos principais desafios enfrentados na questão da formação, a cooperação com a Universidade, cabendo a esta proporcionar aos profissionais dos museus "os valiosos recursos de seus ensinamentos especializados, com seus métodos próprios e seus diplomas renomados" e ao museu proporcionar ao meio universitário o "contato vivificante com as coleções e com os problemas que delas emergem" (RIVIÉRE, 1960, p.15).

Para estudantes interessados em ocupar cargos nos museus, independente da categoria, a orientação era a de oferecer a estes uma formação museológica geral, a ser viabilizada pela cooperação com os museus mais importantes em suas especialidades, respeitadas suas áreas de atuação, a Universidade, o Comitê Nacional do ICOM e/ou com o poder público. A essa 


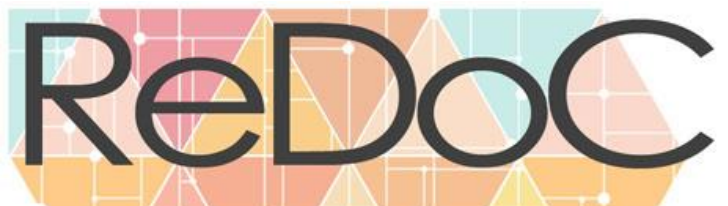

\section{Revista Docência e Cibercultura}

formação se somariam cursos, trabalhos práticos, visitas guiadas, estágios sob a orientação de especialistas renomados. Esses cursos teriam um ano de duração, não demandariam exame de admissão, com uma prova oral e outra escrita ao final. Aprovado em ambas, o estudante teria direito a um título.

O seminário também abordou a formação continuada dos profissionais dos museus, para os quais entende-se que se deveria garantir, a qualquer momento da carreira, meios de aperfeiçoamento em sua especialidade, podendo ser realizada por meio de jornadas de estudo organizadas pela representação do ICOM Nacional ou pela Associação Nacional de Curadores, participação em reuniões de caráter técnico e cientifico sobre museus, visitas a museus, estágios individuais, todos eles podendo ocorrer no país ou no exterior. O texto aborda a importância de autoridades privadas e públicas, bem como da UNESCO, em oferecer o maior número possível de bolsas de aperfeiçoamento para os profissionais já em exercício nos museus, de modo que possam conhecer experiências entendidas como mais avançadas implementadas no exterior. Um dos pontos indicados pelo seminário, tendo como foco a América Latina, dizia respeito à necessidade de se oferecer uma formação técnica e científica realizada com a área de especialidade do profissional de museus, dentre elas a de educação.

Mais recentemente, a formação de profissionais para o campo museal foi retomada na Política Nacional de Museus (2003). Esta prevê a criação de políticas de formação em educação museal e patrimonial, entendidos como campos específicos de atuação. A PNM anuncia a implementação de um programa de formação e capacitação em museus e em museologia envolvendo o aumento da oferta tanto de cursos de graduação e de pós-graduação, quanto de cursos técnicos e de oficinas de extensão, bem como a criação de pólos de capacitação e a existência de equipes volantes que pudessem atuar em nível nacional, o desenvolvimento de programas de estágio em museus brasileiros e estrangeiros, além da inclusão, nos currículos da Educação Básica, de conteúdos e disciplinas referentes ao uso educacional dos museus e dos patrimônios culturais. Entre os efeitos da PNM sobre a formação de profissionais dos 


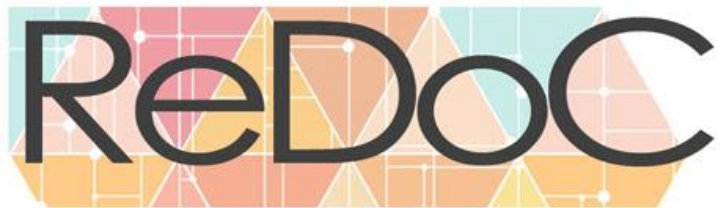

\section{Revista Docência e Cibercultura}

campos museal e museológico podemos citar a significativa ampliação dos cursos de graduação em Museologia no país, passando de apenas 2 existentes em 2003 para cerca de 14 atualmente, e a implementação de uma jornada de oficinas de formação, em especial com tema da educação, promovidos pelo Departamentos de Museus (DEMU/IPHAN) e depois pelo IBRAM. Várias Redes de Educadores de Museus (REMs) tiveram origem a partir das referidas oficinas.

No ano de 2010, a Política Nacional Setorial de Museus (PNSM) também contemplaria a formação de educadores museais. Por meio de um de seus cinco eixos estruturantes, o Cultura, cidade e cidadania, visa a ampliar, qualificar e melhorar o investimento nos quadros de profissionais da ação educativa e sociocultural dos museus. Nesse sentido, apresenta como proposta "a formação e/ou qualificação de pessoal especializado para atuar na área educativa e de serviço sociocultural com vistas a garantir a efetividade de iniciativas voltadas para estreitar a relação do museu com as comunidades, em especial aquelas mais vulneráveis" (IBRAM, 2010, p.16). A formação de educadores museais aparece no PNSM na forma de cursos de formação continuada na área e também de seminários.

A partir de 2017, a questão da formação específica de educadores museais se faz presente no Eixo II da Política Nacional de Educação Museal (IBRAM, 2017). Esta aparece de maneira articulada à "profissionais" e à "pesquisa", devido à natureza altamente imbrincada das referidas dimensões. Como pensar os profissionais e a profissionalização descolados de sua dimensão formativa? Deste modo, a primeira diretriz do referido Eixo aponta para a necessidade de "promover o profissional de educação museal, incentivando o investimento na formação específica e continuada de profissionais que atuam no campo." E como vislumbrar uma formação específica sem pesquisa e geração de conhecimento no campo de atuação? Nesse sentido, destacamos a quinta diretriz que aponta o ensejo de

potencializar o conhecimento específico da educação museal de forma a consolidar o campo, por meio da difusão e promoção dos trabalhos realizados, do intercâmbio de experiência e do estímulo à viabilização de cursos de nível superior em educação museal (IBRAM, 2017) 
O entendimento acerca das especificidades da função educativa das instituições museais passou por importantes transformações, no entanto pouco se avançou no que diz respeito à formação dos educadores museais. A literatura sobre o tema constata, ainda hoje, a pouca presença de instâncias acadêmicas voltadas para a formação profissional dos educadores museais, predominando entre estes a formação no desenvolver da propria prática profissional.

No presente artigo abordaremos discussões acerca do perfil dos educadores museais, das práticas e dos desafios referentes à formação inicial e continuada destes, tanto no cenário nacional quanto no internacional. Fazemos considerações acerca de iniciativa voltada à formação de profissionais nesse campo em nível de pós-graduação, bem como de ações em diferentes formatos desenvolvidas mais recentemente no Rio de Janeiro.

\section{A formação dos educadores museais fora do Brasil}

Por meio de uma breve revisão de literatura acerca da profissionalização e formação de educadores museais produzida fora do Brasil é possível perceber muitos desafios comuns a serem superados lá e cá.

Vera Zolberg (2015) em seu artigo "Barreira ou Nivelador? O caso do Museu de Arte", texto originalmente escrito nos anos de 1990, aborda a profissão e a formação do educador de museu, termo utilizado pela autora, no âmbito dos museus de arte estadunidenses e promove uma comparação com o contexto francês. A autora destaca a hierarquização existente na estrutura interna dos museus, no seio da qual os educadores museais são sobrepujados pelos curadores. Em relação à formação destes se espera que tenham Doutorado em História da Arte (no caso daqueles que atuam nos museus de arte), enquanto a função do educador de museu ainda é encarada como uma atividade voluntária a ser administrada por mulheres com mestrado.

A ideia de que não se necessita de profissional do campo da Educação nos museus de arte 


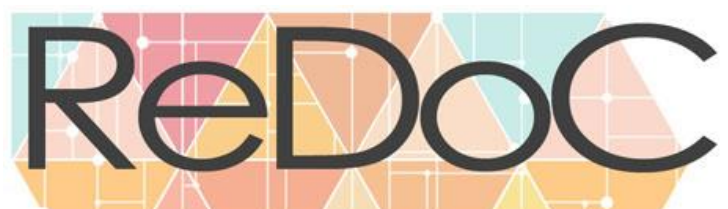

\section{Revista Docência e Cibercultura}

acaba por desencorajar o desenvolvimento da profissão e de uma formação específica em faculdades ou escolas de educação, haja vista que as mesmas "só serviriam para munir os alunos de requisitos vazios e limitar o acesso dos mesmos às artes liberais" (ZOLBERG, 2016, p.267). Uma outra ideia presente naquele momento e também críticada por Zolberg é a de que a função de educar, ao demandar dos profissionais a compreensão de técnicas de ensino, faria com estes as apreendessem ao custo de terem pouco domínio dos conteúdos a serem "transmitidos" ao público.

Para Zolberg (2015), o educador de museus de arte nos Estados Unidos é considerado, quanto muito, um técnico e ela afirma que o desenvolvimento da profissão na França é ainda menor. Por meio da análise de documentos voltados para a capacitação profissional das equipes de museus elaborados nos anos de 1970 e 1980 pelo governo francês, Vera Zolberg aponta para o predomínio de conteúdos ligados à adminsitração e arte em relação aos de educação museal, assim como também tem mais destaque o espaço destinado aos curadores e restauradores, por exemplo. Nesse contexto, os educadores de museu estão alocados sob o cargo de "animateur" e desses se espera um diploma na área ou algum treinamento enquanto cursam artes ou educação geral.

O artigo The Uncertain Profession, de 1987, é bastante citado em trabalhos que tem como foco a profissionalização do educador museal. Nele, os autores se pautam exatamente na ausência de uma preparação acadêmica padrão para o desempenho do trabalho para colocar em dúvida a qualidade da educação museal como profissão (DOBBS, EISNER, 1987).

Tran (2008) focou em seu artigo na profissionalização de educadores museais de centros e museus de ciência. Apesar de no título do trabalho lançar mão do termo educador, ao longo do texto a autora usa muitas vezes a designação explainers e não educadores para se referir aos mesmos. Segundo ela, a literatura sobre o tema aponta tanto para a grande variedade de termos para identificar os educadores museais, quanto para a diversidade de formação acadêmica dos mesmos e de sua titulação, podendo variar de pessoas com nenhuma formação 


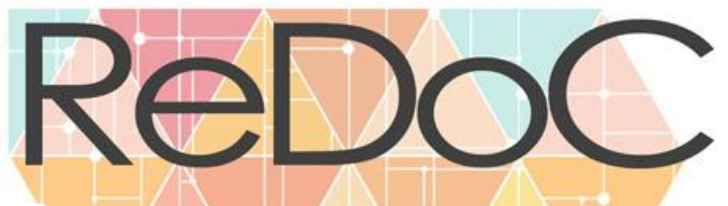

\section{Revista Docência e Cibercultura}

a profissionais com certificados formais de ensino. A diversidade de experiências e de conhecimentos, que por um lado possuem alto valor para o campo da educação museal, por outro acabam contribuindo para a uma pobre definição e baixo reconhecimento dos papeis e da expertise dos educadores museais, fazendo com que se questionasse a relevância profissional do educador museal nos Estados Unidos.

Tran (2008) registra que os educadores museais muitas vezes dão início à sua atuação na área tendo experiências e formações bastante variadas, que podem não ter diretamente relação nem com o meio museal e nem com o campo da educação. Outro agravante é o fato de não haver requisito para obter conhecimentos a fim de se formar como educador museal. Sendo assim, a autora denuncia que a falta de reconhecimento e compreensão acerca do trabalho dos educadores museais, tanto no contexto prático quanto da pesquisa, se deve à ausência de um processo de preparação profissional construído sobre uma base de conhecimento para a pedagogia em espaços museais e de um modelo amplamente compartilhado de prática baseado naquele corpo de conhecimentos e habilidades.

No contexto português, Oliveira (2010) conduziu uma pesquisa que teve como sujeitos 41 educadores museais (31 mulheres) e 3 coordenadoras de educação de três museus de arte. Por meio dela, a autora verificou além da predominância feminina entre os referidos profissionais, algo que parece ser regra no campo da educação museal, a formação acadêmica bastante diversa de seus praticantes. Foram identificados 19 cursos diferentes, desde licenciatura em Biologia, passando por Engenharia do Ambiente, Piano Clássico e Arte/Educação. Uma mudança observada pela pesquisadora com base no perfil dos educadores museais estudados foi a constatação de que todos são graduados, sendo que mais da metade tinha ao menos uma pós-graduação, ao contrário do que se observava nos anos anteriores ao estudo, em os estudantes universitários predominavam no exercício do cargo de educadores museais.

Uma fragilidade do campo, a falta de formação dos profissionais em educação museal, foi também verificada por Oliveira (2010) nos museus estudados, ao passo que um percentual 


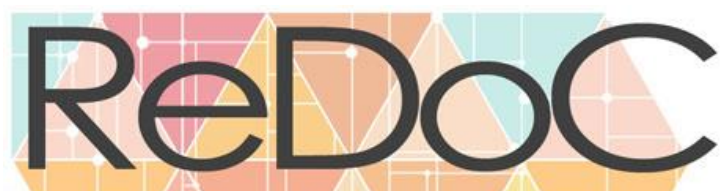

\section{Revista Docência e Cibercultura}

bastante significativo dos pesquisados informou nunca ter realizado qualquer formação na área (39\%). Entre aqueles que disseram terem passado por algum tipo de ação formativa, 34\% citaram formação de curta duração (de um fim de semana até seis meses) e $27 \%$ relataram a realização de seminários durante estágio profissional ou Mestrado.

A pesquisadora identificou que o tipo de vínculo que predomina entre os educadores e suas instituições, o de contratos temporários, somado às poucas oportunidades de formação específica em educação museal, em nada favorecem a formação no campo. Por atuarem simultaneamente em vários museus e até mesmo exercerem paralelamente outras atividades, ainda que a formação seja oferecida, os praticantes não dispõem de tempo para investir nela.

Oliveira (2010) constata que a educação museal é uma profissão incerta, instável, que não conta com uma cultura acadêmica educativa e, nesse contexto, a formação deve ser encarada como uma demanda urgente do campo. Contudo, existe um interesse restrito por parte das universidades portuguesas em relação às especializações em educação museal e os mestrados e pós-graduações oferecidas adotam um currículo genérico que comumente conta com um seminário sobre o referido campo. 


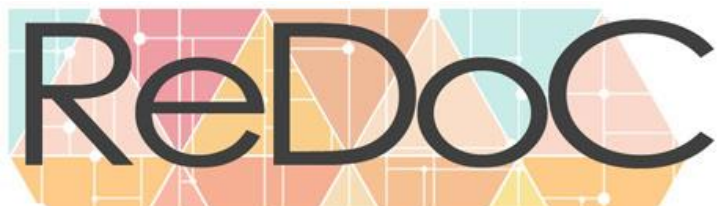

\section{Revista Docência e Cibercultura}

O Journal of Museum Education publicou em 2012 um dossiê temático intitulado "Prática Profissionalizante. Um olhar crítico sobre as práticas recentes na educação de museus”. Neste, vários autores predominantemente estadunidenses, abordam o tema da profissionalização dos educadores museais evidenciando muitas vezes sua relação com a temática da formação. A elaboração do dossiê parece surgir da necessidade de se fazer frente à ideia de pós-profissionalização do educador museal, que coloca o mesmo no lugar de um produtor que lança mão de experiências e habilidades oriundas de outros campos e profissões, como atores, músicos, artistas visuais. A constatação de que as habilidades dos referidos profissionais são pouco valorizadas, bem como da ausência de uma compreensão mais coesa da profissão, assim como citadas por Tran (2008), também são apontadas pelos organizadores do volume. (RASMUSSEN; WINTERRWOWD, 2012)

O perfil e a formação dos educadores e das educadoras museais no Brasil: um exercício de prospecção

O campo da educação museal carece de estudos, levantamentos e diagnósticos que tenham como foco o perfil dos profissionais brasileiros que atuam no mesmo, de modo que possamos conhecer melhor seus percursos acadêmicos e formativos a nível regional e também nacional. Alguns dos estudos existentes no Brasil tem como sujeitos aqueles que atuam nos museus como mediadores. De acordo com Marandino (2008a), no país o mais comum é que sejam selecionados dentre os universitários de acordo com as áreas de conteúdo específicos do museu, com vistas garantir o rigor conceitual, havendo também, segundo a autora, experiências interessantes de estudantes de ensino médio atuando como mediadores em museus. Em alguns casos, os profissionais possuem alguma formação inicial no campo da educação.

Valéria Alencar (2008) realizou uma pesquisa junto a 100 educadores - mediadores culturais - em atividade em exposições de artes visuais na cidade de São Paulo. Por meio desta, gerou dados acerca do perfil dos profissionais em questão, bem como buscou compreender se a 


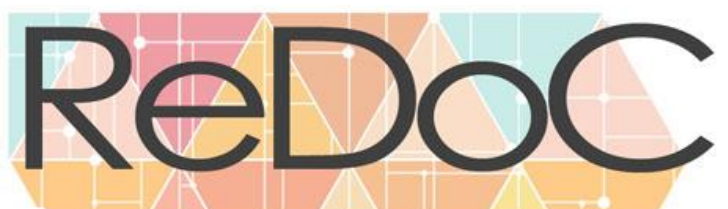

\section{Revista Docência e Cibercultura}

formação inicial destes, obtida por meio dos cursos de graduação, é suficiente para o desempenho de suas atividades. Também buscou avaliar a formação continuada promovida pelas instituições na qual atuam, formação esta dividida pela autora em duas etapas treinamentos ou formações promovidas antes do início das atividades laborais e o processo de formação realizado durante o desenvolvimento das atividades profissionais.

Assim como verificado por Oliveira (2010) nos museus de arte portugueses, Alencar (2008) constatou o predomínio de mulheres (78\%) entre os sujeitos pesquisados, de jovens de até 29 anos $(67 \%)$, de profissionais graduados (74\%), sendo que $42 \%$ possuíam pós-graduação. Entres os cursos de origem dos investigados predominam artes e áreas afins das ciências humanas - fotografia, cinema, publicidade, moda, teatro, arquitetura, desenho industrial e design (70\%). Ao levantar dados acerca da oferta de formação para exposições, $86 \%$ dos pesquisados informaram ter passado por ela. Esse tipo de formação, é frequente em instituições que trabalham com exposições de curta duração e tem em média duração de uma semana, podendo variar de $25 \mathrm{~h}$ a $80 \mathrm{~h}$ de carga horária total e, na maior parte dos casos, é remunerada. Os museus, por não exibirem exposições de curta duração, não costuma oferecer uma formação sistematizada aos seus educadores, segundo a autora.

A formação contínua promovida pela instituição se mostrou uma realidade para a maior parte dos educadores (72\%), contudo o estudo realizado por Alencar (2008) mostra que a mesma pode variar muito de uma instituição para a outra. Sem ignorar o aprendizado obtido na prática e o papel da busca individual pelo aprimoramento da formação do educador, a autora reforça a relevância da formação continuada, feita de maneira coletiva e institucionalizada, ao passo que é nesse contexto que, segundo ela, se reflete sobre a ação, sendo esta reflexão construída a partir de conflitos, problemas e conquistas originadas no cotidiano laboral, viabilizando possibilidades para o aprimoramento do trabalho e compartilhamento de experiências. 


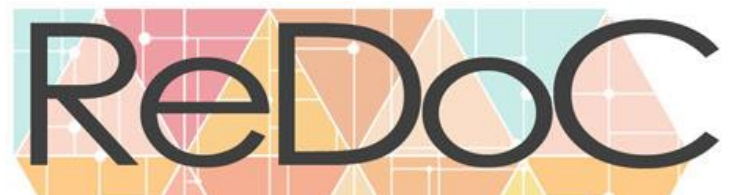

\section{Revista Docência e Cibercultura}

Gomes e Cazelli (2016) analisaram os processos de formação de mediadores em dois museus de ciência situados na cidade do Rio de Janeiro, com ênfase na compreensão dos saberes transmitidos pelos museus. As pesquisadoras investigaram o objeto a partir da perspectiva dos mediadores e das instituições em que atuam, por meio da observação dos cursos oferecidos, de entrevistas com os responsáveis por estes e pela formação em serviço e da aplicação de um questionário autoadminsitrado junto aos mediadores.

Nesse contexto, as pesquisadoras verificaram diferenças nos perfis dos mediadores, predominando em uma delas as mulheres, estudantes de ensino médio com idade média de 21 anos, enquanto na outra os homens eram maioria, assim como também os graduandos e a média de idade era mais elevada, 27 anos.

Os cursos oferecidos pelas instituições pesquisadas por Gomes e Cazelli (2016) têm em comum a curta duração, o interesse em fornecer aos mediadores que iniciam suas trajetórias no campo as ferramentas consideradas básicas para o desempenho de suas funções, recorrendo para isso á apresentação de atividades implementadas pelos museus, embasadas nos conteúdos teóricos das ciências de referência, da educação museal e experiências anteriores. Contudo, diferenças entre eles também são observadas. Enquanto no Espaço Ciência Viva é dado maior destaque aos saberes disciplinares (da Física, Química e Biologia), no MAST a ênfase está nos saberes da formação profissional, descritos pelas autoras como teorias provenientes do campo da educação museal que servem de embasamento para a mediação humana.

As autoras acima citadas também analisaram a formação dos mediadores após a conclusão do curso e identificaram nas instituições como ações voltadas à formação em serviço: a realização de reuniões periódicas, a observação de mediadores mais experientes, estudo dirigido, capacitações pontuais voltadas para atividades específicas, participação de membros da equipe em cursos externos, seminários e palestras. Porém, as mesmas apontam que essas ações muitas vezes ocorrem informalmente, sem o devido planejamento e com caráter não 


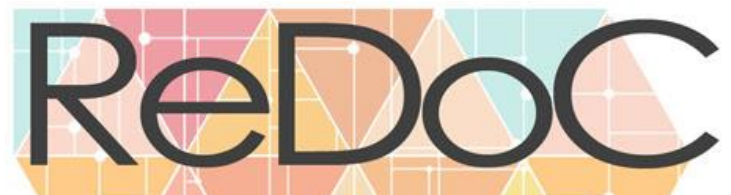

\section{Revista Docência e Cibercultura}

obrigatório. Sinalizam, ainda, que devido à elevada rotatividade dos mediadores, não é incomum que alguns deles estejam em atividade sem que tenha passado por cursos de formação, contando somente com a observação dos mais experientes como fonte de capacitação.

Isso foi constatado em pesquisa que traçou o perfil dos mediadores que atuam em museus e centros de ciência do Brasil (CARLÉTTI e MASSARANI, 2015), segundo a qual a maior parte dos mediadores participantes da pesquisa (61,6\%) informaram não terem passado por uma capacitação antes de iniciar suas atividades de mediação, contando apenas com instruções repassadas por mediadores mais experientes. Por outro lado, de acordo com o mesmo estudo, $71,1 \%$ dos respondentes afirmaram que receberam algum curso de capacitação ao longo de sua atuação, visando o aprimoramento do trabalho após o início de suas atividades.

Assim como verificado por Alencar (2008) nas instituições voltadas às artes visuais, também nos museus de ciência se atribui grande valor às trocas de experiências e à formação em serviço, o que pode ser indicativo das dificuldades enfrentadas pelas instituições museais para promover uma formação mais sistemática e integral. Parecemos constatar o predomínio do modelo centrado na relação aprendiz-mestre, em que o processo de formação baseia-se na observação do trabalho realizado por mediadores mais experientes e considerados competentes, de modo que os novos mediadores percebam as estratégias de mediação adotadas pelos mais antigos e possam assim reproduzi-las (MARANDINO, 2008b). Segundo Gomes e Cazelli (2016), é importante que sejam criados espaços próprios para a troca de conhecimentos teóricos e práticos, envolvendo também o registro das atividades realizadas visando à formalização das experiencias adquiridas e viabilização de seu compartilhamento.

Com vistas a contribuir para a melhor compreensão do perfil de educadores museais brasileiros, procedemos uma análise descritiva de dados gerados nos anos de 2014 e 2017 pela Rede de Educadores em Museus e Centros Culturais do Rio de Janeiro (REM-RJ) junto a 


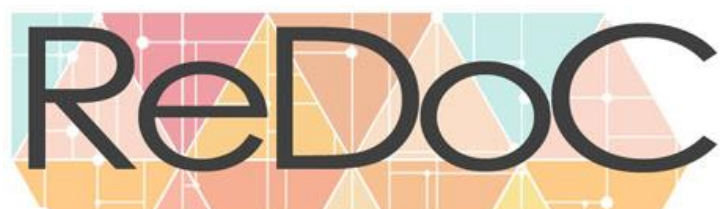

\section{Revista Docência e Cibercultura}

seus integrantes ${ }^{2}$. Nos dois anos citados, o Comitê Gestor da REM-RJ, visando a conhecer melhor os seus membros, bem como seus desejos e anseios em relação à mesma, concebeu um formulário eletrônico que foi simultaneamente enviado para a lista de e-mails da REM-RJ e disponibilizado no grupo fechado que a mesma mantém no Facebook. Ao todo foram obtidas 205 respostas, 139 em 2014 e 66 em 2017.

A maior parte dos respondentes informou atuar em instituição cultural (60\% em 2014 e 69\% em 2017). Por meio da análise dos dados pode-se verificar o predomínio de mulheres (80\% em 2014 e $65 \%$ em 2017) e de pessoas com idade entre 30 e 39 anos (25\% em 2014 e 39\% em 2017). Entre os participantes predominam aqueles que possuem graduação como maior titulação (49\% em 2014 e 44\% em 2017), seguidos pelos que possuem pós-graduação (37\% em 2014 e $45 \%$ em 2017). A maior parte possui ou cursa uma licenciatura (69\% em 2014 e 67\% em 2017) e entre as áreas de formação dos respondentes observamos a maior presença de profissionais dos campos da Pedagogia (25\% em 2014 e 15\% em 2017), História (21\% em 2014 e 15\% em 2017), Museologia (12\% em 2014 e 15\% em 2017) e Educação Artística (11\% em 2014 e 12\% em 2017). O tipo de vínculo que predomina entre os respondentes é o de servidor público (39\% em 2014 e 44\% em 2017), enquanto os prestadores de serviço representam 16\% (2014) e 18\% (2017) dos respondentes.

A relevância das discussões acerca da formação pode ser aferida pelo elevado grau de interesse que os temas formação profissional e formação de mediadores despertam nos respondentes. Os mesmos foram classificados tanto na rodada 2014, quanto na realizada em 2017, entre os quatro temas de maior interesse dos participantes, juntamente com elaboração de projetos educativos e a inclusão sociocultural.

Dois trabalhos nos apresentam análises acerca da presença da educação museal e da educação não formal nas matrizes curriculares de dois dos cursos de graduação que figuram entre os

\footnotetext{
${ }^{2}$ A presente autora foi responsável pela geração dos dados analisados juntamente com Fernanda Castro, Diogo Tubbs e Kátia Frecheiras, todos membros do Comitê Gestor da REM-RJ.
} 


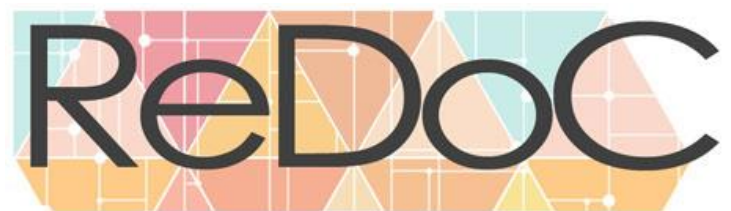

\section{Revista Docência e Cibercultura}

mais citados pelos integrantes da REM-RJ. Por meio da análise dos currículos de cursos de Pedagogia das universidades de maior destaque do Rio de Janeiro, Souza (2016) concluiu que neles estão, na maior parte das vezes, ausentes componentes curriculares que contemplem aspectos da educação não formal, modalidade educacional na qual muitos autores inserem o trabalho educativo dos museus. Já Fernanda Castro ${ }^{3}$ realizou um levantamento referente às disciplinas ligadas à Educação oferecidas por treze cursos de Museologia de universidades públicas brasileiras. O levantamento em questão, que considerou exclusivamente a análise das grades curriculares dos mesmos, identificou que doze dos trezes cursos oferecem ao menos uma disciplina de Educação, sendo que oito deles possuem ao menos uma disciplina obrigatória de Educação e três ao menos uma optativa. No que se refere às obrigatórias, 4 cursos oferecem duas disciplinas ( $\mathrm{N}=4$ em 9), 3 (em 9) oferecem uma única disciplina e 1 dos cursos (em 9) oferece cinco disciplinas obrigatórias. Dos 13 cursos, 5 deles oferecem disciplinas de Educação obrigatórias e optativas. Sendo assim, ainda que conclua que a presença da educação museal nos bacharelados em Museologia é pequena em relação a outras áreas de interesse contempladas pelo mesmo, os museólogos brasileiros têm mais chances do que os licenciados de ter contato com o campo da educação museal durante a sua formação.

No entanto, as pesquisas de Alencar (2008) e de Gomes e Cazelli (2016) verificaram que a educação museal, mesmo não estando muitas vezes contemplada na formação inicial dos praticantes do campo, estes não revelam perceber distanciamento entre o trabalho que realizam (prática) e a formação que receberam (teoria). A partir de tal constatação algumas indagações nos parecem pertinentes e demandam maior reflexão e discussão. Seria a mesma reflexo do fato da educação museal ser um campo ainda em construção? Da inexistência de um espaço ou ferramenta (cursos, revistas, fóruns, etc.) que organize seus conhecimentos teóricos de maneira a serem reconhecidos como um escopo específico? Ou, ainda, resultado de sua desconsideração enquanto campo teórico específico diante de sua prática marcada por saberes múltiplos?

3 O levantamento e a discussão feitos pela autora estão disponíveis em: http://educacaomuseal.org/iniacutecio/educacao-museal-e-museologia 
Em relação à presença da Educação Museal na pós-graduação, há pelo menos dois exemplos históricos que podem ser citados: a criação da pós-graduação em museologia da FAPESP, em 1974, por iniciativa de Waldisa Rússio e, em 1983, da especialização em ação educativa cultural da UNIRIO. Este não teve turma concluída, contudo algumas monografias desenvolvidas no âmbito do curso podem ser encontradas no Museu Histórico Nacional.

Frecheiras e Castro (2018) apresentam as motivações, o desenvolvimento e a avaliação referentes a mais recente experiência de formação no campo em nível de especialização. Implementada entre os anos de 2013 e 2016, foi produto da cooperação técnica entre o Instituto Brasileiro de Museus (IBRAM), representado por dois museus ligados à autarquia, Museus Castro Maya e Museu da República, e a Fundação de Apoio à Escola Técnica (FAETEC), por meio do Instituto Superior de Educação (ISERJ). A existência de demanda por essa formação pode ser confirmada considerando que em apenas uma semana, 127 pessoas se inscreveram para concorrer às 15 vagas reservadas para servidores, funcionários ou ex-alunos dos cursos superiores do ISERJ, outras 15 disponíveis para profissionais com no mínimo 3 anos de experiências comprovada no campo museal e outras 15 para ampla concorrência, totalizando 45 vagas. Entre os que participaram do processo seletivo, a grande maioria, 91, concorreu às vagas de ampla concorrência, 25 concorreram às voltadas para 0 ISERJ e 11 se enquadravam no perfil de profissionais de museus.

Em relação ao perfil acadêmico dos aprovados, chama atenção a presença de licenciados (32), sendo os demais bacharéis. Foram verificadas 9 licenciaturas diferentes cursadas pelo discentes, com destaque para Pedagogia (12) e História (7). Entre os 8 cursos de bacharelado representados, observou-se uma frequência maior de egressos do curso de Museologia (6). Interessantes que os dados apresentados pelas autoras são bem semelhantes aqueles verificados entre os integrantes da REM-RJ.

O curso contou com carga horária total de 380 horas, com aulas presenciais aos sábados. Foi estruturado em 4 módulos que abarcaram as 8 disciplinas ministradas, sendo elas História da 


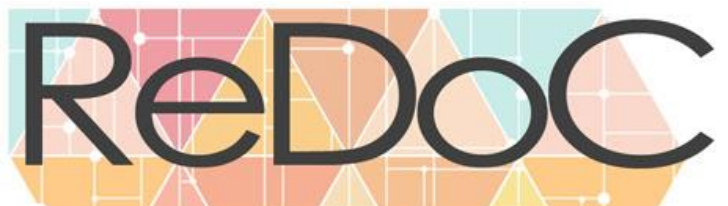

\section{Revista Docência e Cibercultura}

Educação Museal e Fundamentos da Educação (módulo I - 100 h), Laboratório de Metodologias; Formação e Pesquisa em Educação Museal e Conceitos Fundamentais da Educação Museal (módulo II - 80 h), Políticas Públicas de Educação Museal e Metodologia Científica I (módulo II - 80 h) e Laboratório Experimental: Vistas Técnicas (articulação teoria-prática) e Metodologia Cientifica II (módulo IV - 70 horas para orientação e produção científica com 10 horas de encontros coletivos, totalizando $120 \mathrm{~h}$ ). Dos cursistas, 30 concluíram o curso, mediante a apresentação de um artigo final, pré-requisito para obtenção do título. Os artigos deveriam estar vinculados a uma das cinco linhas de pesquisa do programa: Construção Histórico-Conceitual e Práxis em Educação Museal, Práticas em Educação Museal, História das Ideias na Educação Museal, Políticas Públicas para o campo da Educação Museal e Educação, Museu, Cultura e Memória.

No que se refere à avaliação do curso, observou-se dificuldades por parte dos discentes em relação a frequência às aulas, realizadas semanalmente, aos sábados, entre $8 \mathrm{~h}$ e $17 \mathrm{~h}$, bem como também em relação a carga de leitura, que costumava ser de 4 artigos, 1 por disciplina, a serem lidos por semana. Para minimizar o problema, durante a realização do curso, as aulas passaram a ser quinzenais, contudo as sugestões dos alunos para novas edições do curso consistem em sua realização durante a semana em horário noturno e a adoção de um modelo semi-presencial, haja vista que muitos residem fora da cidade do Rio de Janeiro.

Uma única turma foi formada e a iniciativa, apesar de bem-sucedida, não teve continuidade. Frecheiras e Castro (2018, p.406) apontam como causas principais da descontinuidade do curso a crise financeira que afetou o estado do Rio de Janeiro com implicações sobre a Faetec, bem como afastamentos e mudanças de profissão e de instituição de docentes envolvidos na realização do mesmo., a permanente falta de verbas e algumas dificuldades relacionadas à gestão da parceria.

Recentemente foi criada, no Museu Histórico Nacional (MHN), uma importante iniciativa voltada para a formação continuada no campo da educação museal, envolvendo a produção 


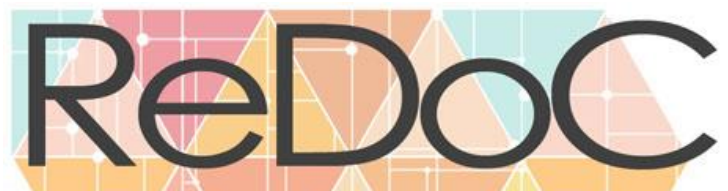

\section{Revista Docência e Cibercultura}

de conhecimento de informação sobre o mesmo, bem como a elaboração teórica coletiva e a construção de ferramentas e metodologias aplicáveis à prática educativa em museus. Trata-se do Grupo de Pesquisa "Educação museal: conceitos, história e políticas”, inicialmente uma linha vinculada ao grupo de pesquisa "Escritas da história em museus: objetos, narrativas e temporalidades" do diretório do IBRAM no CNPq, em 2019 o grupo tornou-se autônomo e promove atividades mensais voltadas a educadores, profissionais de museus, pesquisadores e estudantes, que incluem cursos, mesas redondas, encontros, seminários e apresentações de pesquisas.

Também no MHN, o Núcleo de Educação do Departamento de Dinâmica Cultural, com a colaboração da Escola de Museologia da UNIRIO e da Coordenação de Museologia Social e Educação - COMUSE/IBRAM, promoveu no ano de 2019 dois cursos: o "Curso Básico de Educação Museal", com o objetivo de introduzir a educação museal como conceito, prática e tema de estudo e pesquisa e o "Curso de Elaboração de Programa Educativo e Cultural”, que visou à apresentação do Programa Educativo e Cultural a partir de sua definição como uma Política Educacional, de acordo com as orientações da Política Nacional de Educação Museal. No âmbito do curso básico, seus participantes redigiram um manifesto (Anexo) no qual, dentre outras coisas, são colocadas as demandas de seus profissionais por formação inicial e continuada.

É importante ressaltar a indiscutível relevância da sociedade civil organizada, por meio das Redes de Educadores de Museus (REMs), na criação e viabilização de espaços de formação votados para os educadores museais presentes em pelo menos 19 dos estados brasileiros, incluindo mais recentemente as do Paraná e do Distrito Federal.

\section{Considerações Finais}

Ainda é pequena a visibilidade da Educação Museal nas matrizes curriculares de Pedagogia e Museologia, dois cursos de graduação nos quais vêm se formando um importante número 


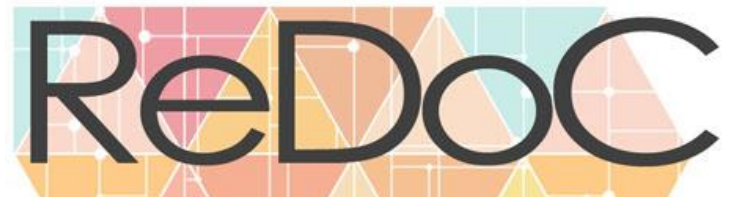

\section{Revista Docência e Cibercultura}

daqueles que atuam ou pretendem atuar como educadores e educadoras museais. Nesse sentido, apontamos que os cursos de graduação deixam de oportunizar para a maior parte de seus discentes a possibilidade de vislumbrar a inserção em um importante e crescente campo de atuação profissional. Perdem os estudantes e perdem também os museus, em especial seus setores educativos.

É possível que o perfil dos educadores museais seja, em grande parte, circunstanciado pelas instituições que selecionam os mesmos, fazendo-a com base na formação inicial e experiências no campo (ALENCAR, 2008). Sendo assim, a prevalência na educação museal de profissionais com determinadas formações pode ser dever mais a um perfil desejado pelos gestores de museus e centros culturais, a partir da identificação de campos que mais se aproximariam do meio museal, do que à própria formação oferecida em seus cursos.

É alarmante constatar que no Rio de Janeiro, onde se situa o mais antigo museu brasileiro Museu Nacional/MN e o primeiro setor educativo de um museu do país - a Seção de Assistência ao Ensino/MN, o primeiro curso de Museologia do Brasil, a Escola de Museologia da UNIRIO - antigo Curso de Museus do Museu Histórico Nacional, cidade na qual foi criada a primeira Rede de Educadores de Museus e que foi sede do Seminário da UNESCO de 1958 sobre a função educativa dos museus, apesar das diversas tentativas ensejadas não se tenha reunido até hoje condições para promover, de maneira ampla, regular e estruturada, a formação inicial e continuada de profissionais do campo da educação museal no Brasil.

Formação e profissionalização são faces de uma mesma moeda. Uma vez que a educação museal não é ocupação registrada na Classificação Brasileira de Ocupações (CBO) e nem profissão regulamentada, não há exigência de uma formação mínima. A inexistência dessa, por sua vez, não favorece a profissionalização.

Para o campo da educação museal, a formação é certamente hoje um de seus maiores desafios e elemento chave de seu fortalecimento teórico e profissional. Nos falta concretizar muito do 


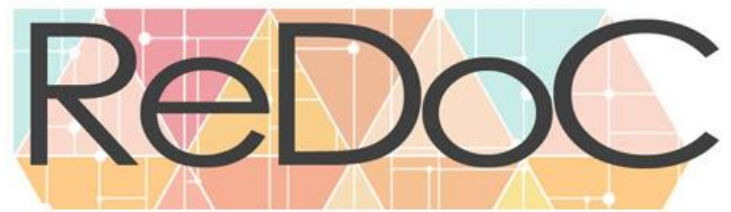

\section{Revista Docência e Cibercultura}

que foi anunciado em meados do século passado em relação ao tema e isso envolve mobilizar e articular museus, Universidades (graduação e pós-graduação), organismos de classe, políticas públicas, agências de fomento, dentre outros. Entendemos que consolidar ações voltadas à formação inicial e continuada de educadores museais faz parte do processo de elevar - na prática - o status da educação no contexto museal, melhorando a educação brasileira e tornando os museus e a sociedade mais democráticos.

\section{REFERÊNCIAS}

ALENCAR, Valéria P. O mediador cultural: considerações sobre a formação e profissionalização de educadores de exposições e museus de arte. Dissertação (Mestrado) - Universidade Estadual Paulista, Instituto de Artes, São Paulo, 2008.

CARLÉTTI, Chrystian; MASSARANI, Luisa. Mediadores de centros e museus de ciência: um estudo sobre quem são estes atores-chave na mediação entre a ciência e o público no Brasil. Journal of Science Communication, v. 14, n. 2, p. 1-17, 2015.

DOBBS, Stephen M.; EISNER, Elliot W. The Uncertain Profession: Educators in American Art Museums. Journal of Aesthetic Educacion. v.21, n.4, 1987.

FRECHEIRAS, Kátia; CASTRO, Fernanda. A PNEM e os subsídios para profissionais, formação e pesquisa: relato de uma experiência acadêmica. In: TOJO, Joselaine M.; AMARAL, Lilian (orgs.). Rede de Redes-diálogos e perspectivas das redes de educadores de museus no Brasil, São Paulo, 2018. Disponível em: https://www.sisemsp.org.br/redederedes> Acesso em: 18 ago 2019.

GOMES, Isabel; CAZELLI, Sibele. Formação de Mediadores em Museus de Ciência: Saberes e Práticas. Ensaio Pesquisa em Educação em Ciências, Belo Horizonte, v.18, n.1, p.23-46, mar. 2016.

IBRAM. Plano Nacional Setorial de Museus - 2010/2020. Ministério da Cultura, Instituto Brasileiro de Museus: Brasília, DF: MinC/Ibram, 2010.

IBRAM. Documento Final da Política Nacional de Educação Museal. Brasília, DF: Instituto Brasileiro de Museus, 2017.

IPHAN. Política Nacional de Museus. Brasília, DF: Instituto do Patrimônio Histórico e Artístico Nacional, 2003.

MARANDINO, Martha (org.). Educação em museus: a mediação em foco. São Paulo, SP: Geenf / FEUSP, 2008a.

MARANDINO, Martha. Ação educativa, aprendizagem e mediação nas visitas aos museus de ciências. In: In: MASSARANI, L.; ALMEIDA, C. (Ed.). Workshop Sul-Americano \& Escola de Mediação em Museus e Centros de Ciência. Rio de Janeiro: Museu da Vida/Casa de Oswaldo Cruz/Fiocruz, 2008b. p. 21-28. 


\section{Revista Docência e Cibercultura}

OLIVEIRA, Maria Genoveva M. Educação nos Museus de Arte Moderna e Contemporânea Portugueses: um lugar do feminino? In: SEMEDO, Alice; NASCIMENTO, Elisa N. (coord.) Actas do I Seminário de Investigação em Museologia dos Países de Língua Portuguesa e Espanhola. Porto: Universidade do Porto, 2010, vol.2.

RASMUSSEN; Briley; WINTERRWOWD, Scott. Professionalizing Practice. Journal of Museum Education, v.37, n.2, p7-11, 2012.

RIVIÈRE, Georges-Henri. Stage régional d'études de l'Unesco sur le rôle éducatif des musées. Paris: UNESCO, 1960.

SOUZA, Renata do N. de. O pedagogo e os espaços não escolares: a atuação nos museus. Dissertação (Mestrado) - Pontifícia Universidade Católica do Rio de Janeiro, Departamento de Educação, Rio de Janeiro, 2016

TRAN, Lynn U. The professionalization of educators in science museums and centers. Journal of Science Communication, v.7, n.4, 2008.

ZOLBERG, Vera L. Barreira ou nivelador? O caso do museu de arte. In: LAMONT, Michèle; FOURNIER, Marcel (orgs.) Cultivando diferenças: fronteiras simbólicas e a formação da desigualdade. São Paulo: Edições Sesc São Paulo, 2015.

\section{ANEXO}

\section{MANIFESTO POR UM MUSEU EDUCATIVO (DE FATO)}

A Educação Museal é ação tecida por uma concepção de mundo que quer transformar a sociedade por meio da COLABORAÇÃO, do incentivo à criAÇÃO, contribuindo para a formação integral dos cidadãos e a existência de um museu educativo.

A Educação há muito está presente no museu como dimensão, mas a função da Educação Museal, seu reconhecimento como um campo de atuação profissional, de construção de conhecimento e científico (por que não?) é uma batalha ainda travada pelos profissionais de educação museal.

Entre eles está o EDUCADOR MUSEAL, cuja valorização deve se expressar no incentivo à sua formação - inicial e continuada -, à construção da sua carreira e de parâmetros de remuneração, na consolidação das suas atribuições, na garantia dos recursos, da 


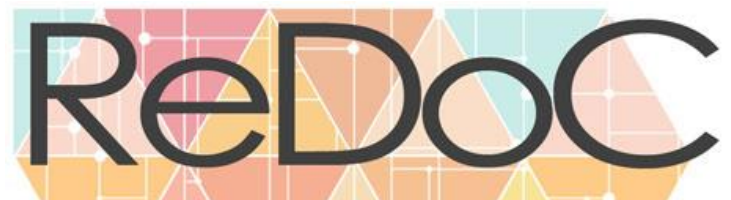

\section{Revista Docência e Cibercultura}

estrutura e infraestrutura, das ferramentas e dos espaços de debate, pesquisa, reflexão e construção coletiva, que são próprios dos processos educativos museais. Os educadores museais, como profissionais, precisam se organizar.

Os educadores museais desejam interagir com os demais profissionais dos museus, em pé de igualdade, de modo integral e integrado, concebendo e implementando de forma participativa todas as ações e processos dos museus. A Educação Museal não deve, assim, ficar relegada a cantinhos, a anexos ou ser convocada apenas no final dos processos iniciados, elaborados e implementados sem educadores. A exposição, a comunicação, a conservação, a gestão, a limpeza, a vigilância, a segurança, tudo tem que estar marcado pela educação, quando falamos de museu.

Museal não é só adjetivo, por isso a Educação Museal se dá no museu, ou não, pelo museu, ou não, na escola, nas ruas, onde não há museu, onde os museus brotam, onde eles são ainda ideias não desabrochadas, no universo da cibercultura. Seu foco está nas pessoas e não nos objetos. Esses são meios pelos quais se desenvolve a ação educativa dos museus.

A Educação Museal tem seus termos, conceitos, referências, modos de fazer. Tem que ter seus espaços, seus modos, seus saberes institucionalizados, nos museus - que são espaços de construção de saber -, nas universidades, nos institutos de pesquisa, na rua, na praça, na boca e na mente-memória do povo. É transversal, articula artes plásticas, música, dança cinema, filosofia, ciência, história, ativa os sentidos e a sensibilidade. É contrária a toda forma de opressão, aos discursos de ódio, intolerância e anti-ciência e toda ameaça ao bem estar social.

A Educação Museal é parte do processo de formação do cidadão, promove a reflexão crítica sobre a realidade em que vivemos, contribuindo para uma consciência quanto à sustentabilidade. É política e fórum permanente de discussão, é trabalho em rede, é troca de experiências, é diálogo com públicos, audiências, comunidades, com o poder público e o privado, o visitante presencial, online e conectado digitalmente, 


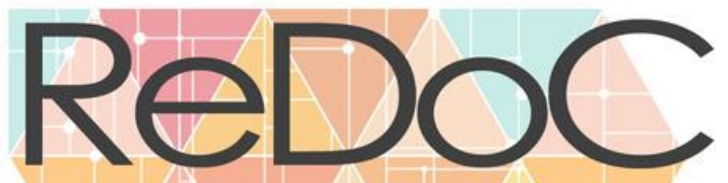

\section{Revista Docência e Cibercultura}

as mães, filhos, pais e avós, gente que pensa, que age, que chora, e constrói o que é arte, ciência, história e patrimônio.

Assinam esse manifesto os Participantes do

Curso Básico | Educação Museal

Museu Histórico Nacional

26 a 28 de março de 2019 